\title{
A PROSPECTIVE STUDY OF MANAGEMENT OF GASTROINTESTINAL ANASTOMOTIC LEAKS IN POPULATION AGED 18 YEARS AND ABOVE IN A TERTIARY CARE HOSPITAL
}

\author{
Dinesh Chaudhari ${ }^{1}$, Abhineet Kumar Jain ${ }^{2}$, Prabhat Shukla ${ }^{3}$
}

${ }^{1}$ Senior Resident, Department of General Surgery, SMBT Medical College, Nashik, Maharashtra, India.

${ }^{2}$ Senior Resident, Department of General Surgery, NSCB Medical College, Jabalpur, Madhya Pradesh, India.

3Junior Resident, Department of General Surgery, NSCB Medical College, Jabalpur, Madhya Pradesh, India.

\section{ABSTRACT}

\section{BACKGROUND}

The study of anastomotic leaks is critically important to surgeons because morbidity and mortality increase many fold in the aftermath of an anastomotic disruption. Anastomotic leaks are one of the most serious complications that occur after gastrointestinal surgery. They increase costs of postoperative patient care, lengthen hospital stay, cause hospital re-admissions and patient morbidities. Further, reoperations and complications such as leaks are considered a quality indicator in gastrointestinal surgery. We wanted to study the frequency of established risk factors for AL, management and outcome based on APACHE II score in a tertiary care hospital.

\section{METHODS}

A prospective interventional study with a total of 30 patients who developed GI leak at M. Y. Hospital January 2016 and July-2017 were included in the study. Ethical committee clearance was taken for the study. Consent from the patients was sought and the purpose of study was explained to patients and their attenders. Details of every patient who developed AL, such as evaluation of contributing risk factors for $\mathrm{AL}$, reason for which operation was done, technique used in operation, and results in terms of length of hospital stay, re-exploration rates, complications and mortality were collected. The APACHE II Score was calculated within 24 hours of diagnosis of AL and again on days 3 and 7. The score was calculated using poorest values during first 24 hours of diagnosis of AL and on days 3 and 7. Failure of GI anastomosis was established when there was frank discharge of enteric contents in drain or through suture line, or if leak was found at contrast radiography or re-exploration for localized/generalized peritonitis or peritoneal abscess.

\section{RESULTS}

Most (40\%) patients were aged 46-60 years with male-to female ratio of 2.7:1. Most (80\%) of them were operated in emergency with small intestine (70\%) being the commonest site of AL. Hemoglobinemia (80\%) followed by blood loss (36.66\%), intra-op contamination $(26.66 \%)$ were the most common risk factors. The overall mortality was $33.33 \%$ in patients who developed anastomotic leaks. Out of 22 cases who were re-operated, only 3 died (10\%), while 7 (23.33\%) cases who were managed conservatively died. The APACHE II scores showed no improvement on days 3, 7 \& 10 in patients who died but continuously decreased in survivors. $100 \%$ mortality was seen in patients with APACHE II score of 25 or greater.

\section{CONCLUSIONS}

Multiple reoperations and stoma creation are often necessary to control the leak, which significantly increases health risks and health care costs up to 5 times that of patients with no leak. Substantial patient morbidity and mortality and poor long-term outcomes are ascribed to anastomotic dehiscence.

HOW TO CITE THIS ARTICLE: Chaudhari D, Jain AK, Shukla P. A prospective study of management of gastrointestinal anastomotic leaks in population aged 18 years and above in a tertiary care hospital. J. Evolution Med. Dent. Sci. 2019;8(21):1747-1750, DOI: $10.14260 /$ jemds/2019/383

\section{BACKGROUND}

Despite most recent advances in surgery, complications still do occur even with experienced surgeons. Anastomotic leak is considered one of the most devastating complications resulting in severe morbidity and mortality. The outcome of bowel anastomosis depends on a number of preoperative, intraoperative and postoperative factors principally the

'Financial or Other Competing Interest': None.

Submission 04-04-2019, Peer Review 10-05-2019,

Acceptance 17-05-2019, Published 27-05-2019.

Corresponding Author:

Abhineet Kumar Jain,

99/27, Shitalpuri Colony,

Baldevbagh Ukhari Road,

Jabalpur-482001,

Madhya Pradesh, India.

E-mail: abhijain2788@gmail.com

DOI: $10.14260 /$ jemds $/ 2019 / 383$

(c) $\underset{\mathrm{BY}}{\mathrm{NC}}(\mathrm{\textrm {NC }}$ suture technique, surgeon's experience, patient's general condition and timing of surgery. It is the surgeon's responsibility to be aware of these factors and give them due consideration while planning a gastrointestinal anastomosis. This study is intended to identify the most prevalent contributing factors and the potential modifications that can be made to reduce the risk of anastomotic leaks following gastrointestinal (GI) surgery.

\section{Aims and Objectives \\ The study was undertaken to study the frequency of established risk factors for $\mathrm{AL}$, management and outcome based on APACHE II score in a tertiary care Hospital.}

\section{METHODS}

A prospective interventional study with total of 30 patients who developed GI leak at M. Y. Hospital between period of January 2016 to July-2017 were included in the study. Ethical committee clearance was taken for the study. 


\section{RESULTS}

\begin{tabular}{|c|c|c|}
\hline Age Group & Number & Percentage \\
\hline $18-30$ & 6 & 20 \\
\hline $31-45$ & 11 & 36.6 \\
\hline $46-60$ & 12 & 40 \\
\hline$>60$ & 1 & 3.3 \\
\hline Total & 30 & 100 \\
\hline \multicolumn{2}{|c|}{ Table 1. Age Wise Distribution of Cases } \\
\hline
\end{tabular}

\begin{tabular}{|c|c|c|}
\hline Sex & Number & Percentage \\
\hline Male & 22 & 73.33 \\
\hline Female & 8 & 26.66 \\
\hline Total & 30 & 100 \\
\hline \multicolumn{2}{|c|}{ Table 2. Distribution of Cases according to Sex } \\
\hline
\end{tabular}

\begin{tabular}{|c|c|c|}
\hline Type & Number & Percentage \\
\hline Elective & 6 & 20 \\
\hline Emergency & 24 & 80 \\
\hline Total & 30 & 100 \\
\hline Table 3. Distribution of Cases: Elective/Emergency \\
\hline
\end{tabular}

\begin{tabular}{|c|c|c|}
\hline Anastomotic Category & Number & Percentage \\
\hline Ileo-ileal & 19 & 63.33 \\
\hline Ileo-colonic & 3 & 10 \\
\hline Jejuno-Jejunal & 2 & 6.66 \\
\hline Gastro-Jejunal & 1 & 3.33 \\
\hline Colo-Colonic & 3 & 10 \\
\hline Hepatico-Jejunal & 2 & 6.66 \\
\hline Total & 30 & 100 \\
\hline
\end{tabular}

Table 4. Distribution of Cases According to Anastomotic Category

\begin{tabular}{|c|c|c|}
\hline Technique & Number & Percentage \\
\hline Single Layer/Continuous & 20 & 66.66 \\
\hline Single Layer/Interrupted & 10 & 33.33 \\
\hline Total & 30 & 100 \\
\hline \multicolumn{3}{|c|}{$\begin{array}{c}\text { Table 5. Distribution of Cases According to } \\
\text { Anastomotic Technique: }\end{array}$} \\
\hline
\end{tabular}

\begin{tabular}{|c|c|c|}
\hline Duration of Stay & Number & Percentage \\
\hline$<10$ & 2 & 6.66 \\
\hline $11-20$ & 22 & 73.33 \\
\hline$>21$ & 6 & 20 \\
\hline Total & 30 & 100 \\
\hline \multicolumn{2}{|c|}{ Table 6. Distribution of Cases According to Duration of Hospital } \\
Stay
\end{tabular}

\begin{tabular}{|c|c|c|}
\hline POD & Number & Percentage \\
\hline$<3$ & 1 & 3.33 \\
\hline $3-4$ & 1 & 3.33 \\
\hline $5-7$ & 27 & 90 \\
\hline$>7$ & 1 & 3.33 \\
\hline Total & 30 & 100 \\
\hline \multicolumn{2}{|c|}{ Table 7. Distribution of Cases According to } \\
POD of Diagnosis of AL \\
\hline Majority (n=27, 90\%) of patients who developed AL were diagnosed \\
between 5th and 7th post-operative day.
\end{tabular}

\begin{tabular}{|c|c|c|}
\hline Primary Method of Diagnosis of AL & Number & Percentage \\
\hline Clinical & 30 & 100 \\
\hline Radiological & 0 & 0 \\
\hline Total & 30 & 100 \\
\hline Table 8. Distribution of Cases According to \\
Primary Method of Diagnosis of AL \\
\hline
\end{tabular}

\begin{tabular}{|c|c|c|}
\hline Management & Number & Percentage \\
\hline Operative & 22 & 73.33 \\
\hline Conservative & 8 & 26.66 \\
\hline Total & 30 & 100 \\
\hline Table 9. Distribution of Cases According to Management of $\boldsymbol{A L}$ \\
\hline
\end{tabular}

\begin{tabular}{|c|c|c|}
\hline $\begin{array}{c}\text { Surgical Intervention } \\
\text { done }\end{array}$ & Number & Percentage \\
\hline Revision of Anastomosis & 3 & 10 \\
\hline Defunctioning Stoma & 19 & 63.33 \\
\hline \multicolumn{2}{|c|}{ Table 10 } \\
\hline
\end{tabular}

\begin{tabular}{|c|c|c|}
\hline Outcome & Number & Percentage \\
\hline Improved & 20 & 66.66 \\
\hline Mortality & 10 & 33.33 \\
\hline Total & 30 & 100 \\
\hline \multicolumn{2}{|c|}{ Table 11. Distribution of Cases According Outcome } \\
\hline
\end{tabular}

\begin{tabular}{|c|c|c|}
\hline Management & Number & Percentage \\
\hline Operative & 3 & 10 \\
\hline Conservative & 7 & 23.33 \\
\hline \multicolumn{2}{|c|}{ Table 12. Distribution of Case Mortality Based on Management } \\
\hline
\end{tabular}

\begin{tabular}{|c|c|c|}
\hline Risk Factor & Number & Percentage \\
\hline Anaemia $(\mathrm{Hb}<10)$ & 4 & 13.33 \\
\hline $\begin{array}{c}\text { Hypoalbuminemia } \\
(\text { Sr. Albumin }<3.2)\end{array}$ & 24 & 80 \\
\hline Diabetes Mellitus & 4 & 13.33 \\
\hline Chronic Smoker & 6 & 20 \\
\hline Chemotherapy & 4 & 13.33 \\
\hline History of RT & 2 & 6.66 \\
\hline Co-morbidities & 5 & 16.66 \\
\hline Blood Loss $>200 \mathrm{ml}$ & 11 & 36.66 \\
\hline Surgery Duration $>200 \mathrm{~min}$ & 4 & 13.33 \\
\hline Intra-op Contamination & 8 & 26.66 \\
\hline
\end{tabular}

\begin{tabular}{|c|c|c|c|}
\hline Group & $\begin{array}{c}\text { Mean Apache II } \\
\text { Score (0) }\end{array}$ & $\begin{array}{c}\text { Mean Apache II } \\
\text { Score (3) }\end{array}$ & $\begin{array}{c}\text { Mean Apache II } \\
\text { Score (7) }\end{array}$ \\
\hline Survivors & $11.5(\mathrm{SD}=2.62)$ & $11(\mathrm{SD}=2.49)$ & $8.6(\mathrm{SD}=1.81)$ \\
\hline Deaths & $23.5(\mathrm{SD}=2.12)$ & $23.7(\mathrm{SD}=2.31)$ & $25.8(\mathrm{SD}=2.29)$ \\
\hline \multicolumn{4}{|c|}{ Table 14 } \\
\hline
\end{tabular}

\begin{tabular}{|c|c|c|}
\hline Complications & Number & Percentage \\
\hline \multicolumn{3}{|c|}{ Early } \\
\hline SSI & 9 & 30 \\
\hline Sepsis & 8 & 26.66 \\
\hline Peritonitis & 5 & 16.66 \\
\hline Wound Dehiscence & 4 & 13.33 \\
\hline Burst Abdomen & 2 & 6.66 \\
\hline MODS & 2 & 6.66 \\
\hline Respiratory Failure & 1 & 3.33 \\
\hline DIC & 1 & 3.33 \\
\hline \multicolumn{3}{|c|}{ Late } \\
\hline Incisional Hernia & 5 & 16.66 \\
\hline Stoma Recede & 1 & 3.33 \\
\hline
\end{tabular}

Consent from the patient was sought and the purpose of study was explained to patients and their attenders. The details of every patient who developed $\mathrm{AL}$, such as evaluation for contributing risk factors for $\mathrm{AL}$, reason for which operation was done, technique used in operation, and results in terms of length of hospital stay, re-exploration rates, complications and mortality were collected. The APACHE II Score was calculated within 24 hours of diagnosis of AL and again on days 3 and 7 . The score was calculated using poorest values during first 24 hours of diagnosis of AL and on days 3 and 7. Failure of GI anastomosis was established when there was frank discharge of eneteric contents in drain or through suture line, or if leak was found at contrast radiography or reexploration for localized/generalized peritonitis or peritoneal abscess. 


\section{Statistical Analysis}

Simple descriptive statistical analysis was used and shown in the following tables and graphs. The study included 22 males $(73.33 \%)$ and 8 females $(26.66 \%)$ giving a male-to female ratio of 2.7: 1 . The mean age of patients was 42.135 (SD 12.13 ) and the age range was from 18 to 61 years. Most (40\%) patients were aged 46-60 years.

Out of the 30 cases of AL, majority were operated in Emergency (80\%) setting and only 6 cases (20\%) who developed AL were operated electively.

The most common site for AL was the ileum (63.33\%), followed by ileocolonic (10\%) and colo-colonic (10\%) leak. Jejunal (6.66\%) anastomotic leak was found in 2 cases. Only a single case of Gastrojejunostomy developed AL.

The commonest anastomotic technique used was found to be single layer continuous suturing technique which was performed in $20(66.66 \%)$ cases.

The minimum duration of hospital stay in cases who developed AL was 11 days and the Maximum duration of stay was 33 days. On average patients stayed in hospital for 16.4 days $(S D=6.09)$. Figure presents distribution of durations of Hospital stay in the study. Most patients $(n=22,73.3 \%)$ were in hospital for between 11 to 20 days.

All cases of AL were diagnosed clinically. Spillage of enteric contents through wound or bilious/faecal collection in drain being obvious signs for diagnosis.

Of the 30 cases of AL, majority of cases were re-operated $(n=22,73.33 \%)$. While conservative management was done in 8 cases $(26.66 \%)$.

The most common surgical intervention was found to be creating a Defunctioning stoma $(n=19,63.33 \%)$.Revision of anastomosis was done in 3 cases (10\%) of AL.

The overall mortality was $33.33 \%$ in patients who developed anastomotic leaks. Out of 22 cases who were reoperated only 3 died (10\%), while 7 (23.33\%) cases who were managed conservatively died.

APACHE II Scores were obtained on the day of diagnosis of AL and again on $3^{\text {rd }}$ and $7^{\text {th }}$ day.

The most common risk factor for AL identified in this study was Hypoalbuminemia $(n=24,80 \%)$ followed by blood loss $(n=11,36.66 \%)$, intra-op contamination $(n=8,26.66 \%)$, Chronic smoking $(n=6,20 \%)$. Other factors identified were Co-morbidities $(\mathrm{n}=5,16.66)$ such as COPD, TB, CAD, DM ( $\mathrm{n}=4$, $13.33 \%)$, Chemotherapy $(n=4,13.33 \%)$, Duration of Surgery $>200 \min (n=4,13.33)$ History of RT $(n=2,6.66 \%)$.

Observed mortality of $100 \%$ in patients with APACHE II score of 25 or greater. The APACHE II scores showed no improvement on days $3,7 \& 10$ in patients who died but continuously decreased in survivors.

The most common early complication found in this study was SSI $(n=9,30 \%)$ followed by sepsis $(n=8,26.66 \%)$, peritonitis $(n=5,16.66 \%)$, Wound dehiscence $(n=4,13.33 \%)$, Burst Abdomen ( $n=2,6.66 \%)$, MODS ( $n=2,6.66 \%)$.

The most common late complication was found to be Incisional hernia $(n=5,16.66 \%)$. A single patient had stoma retraction.

\section{DISCUSSION}

Out of the 30 cases of $\mathrm{AL}$, majority were operated in Emergency (80\%) setting and only 6 Cases (20\%) who developed AL were operated electively. Most common surgical indication was found to be small bowel pathology
(64\%) which included perforation, stricture, diverticuli, obstructed hernia, SMA thrombosis and adhesions secondary to Koch's abdomen. When planning a anastomosis in emergency setting, always consider a covering ileostomy whenever in doubt or risk of leak is anticipated especially in cases of perforation peritonitis.[1-3]

Hypoalbuminemia was present in $80 \%$ of cases, making it the most common definite risk factor in this study. Anaemia $(\mathrm{Hb}<10 \mathrm{~g} / \mathrm{dl})$ was found in $13.66 \%$ of cases. Pre-operative poor nutritional status and Albumin levels lower than 3.2 $\mathrm{mg} / \mathrm{dL}$ is an independent risk factor for $\mathrm{AL}$ and other complications.[4-9]

Superior surgical results are gained in malnourished cases by building up them with high calorie and protein diet 2 weeks prior to a planned surgery.[7,8] Post-operative nutritional support in the form of TPN is required in patients who develop ileus or enteral nutrition is not possible.

In our study, 6 cases had history of neoadjuvant chemotherapy/radiotherapy. Special consideration should be given to Patients who have recently undergone radiation therapy, as some studies show high AL rates in such cases.[10]

In our study, APACHE II Scores were obtained on the day of diagnosis of $\mathrm{AL}$ and again on 3rd and $7^{\text {th }}$ day. The mean APACHE II score (23.5) on the day of diagnosis of AL in cases who died was significantly higher than those of survivors (11.5). We observed mortality of $100 \%$ in patients with Apache II score of 25 or greater. An increasing score should warrant the shift of patient to Intensive care unit and removal of septic focus t earliest.

In this study, out of the 30 patients of $\mathrm{AL}$, most of them were re-explored as soon as AL was established (73.33\%) and a diversion ileostomy was the most preferred. In a few patients who were diagnosed early and had favourable conditions primary anastomosis was revised (10\%).

Non-operative treatment was given in 8 patients (26.66\%).Out of these 2 patients had developed low output ECF and close monitoring was done. Other 6 patients had deteriorated and unstable for re-operation.

All cases of AL in our study were diagnosed clinically. Spillage of enteric contents through wound or bilious/faecal collection in drain being obvious signs for diagnosis. Early detection of AL is crucial for management, as any delay will lead to unfavourable results.[3,11]

In the post-operative period, surgeons should always be alert and should not neglect subtle signs and symptoms such as unexplained fever, arrhythmias, prolonged ileus, PR bleeding, diarrhoea, signs of peritonitis, intra-abdominal abscess, suspicious discharge from suture line or drains. Never hesitate to take a second opinion from a senior, experienced surgeon.

The overall mortality in our study was $33.33 \%$ in patients who developed anastomotic leaks. Out of 22 cases who were re-operated only 3 died (10\%), while 7 (23.33\%) cases who were managed conservatively died. On average patients stayed in hospital for 26.4 days. In three studies, the duration of stay was found to be at least 4 times longer in the hospital for cases with $\mathrm{AL}$ when compared to patients without leak.[12,13,14]

\section{CONCLUSIONS}

The study of anastomotic leaks is critically important to surgeons because morbidity and mortality increase many fold 
in the aftermath of an anastomotic disruption. Anastomotic leaks are one of the most serious complications that occur after gastrointestinal surgery. They increase costs of postoperative patient care, re-operations and stoma creation, lengthen hospital stay, cause hospital re-admissions and patient morbidities.

\section{REFERENCES}

[1] McDermott FD, Collins D, Heeney A, et al. Minimally invasive and surgical management strategies tailored to the severity of acute diverticulitis. The British Journal of Surgery 2014;101(1):e90-e9.

[2] Constantinides VA, Heriot A, Remzi F, et al. Operative strategies for diverticular peritonitis: a decision analysis between primary resection and anastomosis versus Hartmann's procedures. Annals of Surgery 2007;245(1):94-103.

[3] Oberkofler CE, Rickenbacher A, Raptis DA, et al. A multicenter randomized clinical trial of primary anastomosis or Hartmann's procedure for perforated left colonic diverticulitis with purulent or fecal peritonitis. Annals of Surgery 2012;256(5):819-26, discussion 826-817.

[4] Biondo S, Pares D, Kreisler E, et al. Anastomotic dehiscence after resection and primary anastomosis in left-sided colonic emergencies. Diseases of the Colon and Rectum 2005;48(12):2272-80.

[5] Senagore AJ, Delaney CP, Madboulay K, et al. Laparoscopic colectomy in obese and non-obese patients. Journal of Gastrointestinal Surgery: Official Journal of The Society for Surgery of the Alimentary Tract 2003;7(4):558-61.

[6] Kartheuser AH, Leonard DF, Penninckx F, et al. Waist circumference and waist/hip ratio are better predictive risk factors for mortality and morbidity after colorectal surgery than body mass index and body surface area. Annals of Surgery 2013;258(5):722-30.

[7] Krysa J, Patel V, Taylor J, et al. Outcome of patients on renal replacement therapy after colorectal surgery. Diseases of the Colon and Rectum 2008;51(6):961-5.

[8] Golub R, Golub RW, Cantu R Jr, et al. A multivariate analysis of factors contributing to leakage of intestinal anastomoses. Journal of the American College of Surgeons 1997;184(4):364-72.

[9] Slieker JC, Komen N, Mannaerts GH, et al. Long-term and perioperative corticosteroids in anastomotic leakage: a prospective study of 259 left-sided colorectal anastomoses. Archives of Surgery 2012;147(5):447-52.

[10] Smith ST, Seski JC, Copeland LJ, et al. Surgical management of irradiation-induced small bowel damage. Obstetrics and Gynecology 1985;65(4):563-7.

[11] The higher risk general surgical patient towards improved care for a Forgotten Group. https://www.rcseng.ac.uk/publications/docs/higherris surgical patient/.

[12] Akiyoshi T, Ueno M, Fukunaga Y, et al. Incidence of and risk factors for anastomotic leakage after laparoscopic anterior resection with intracorporeal rectal transection and double-stapling technique anastomosis for rectal cancer. Am J Surg 2011;202(3):259-64.

[13] Kockerling F, Rose J, Schneider C, et al. Laparoscopic colorectal anastomosis: risk of postoperative leakage. Results of a multicenter study. Laparoscopic Colorectal Surgery Study Group (LCSSG). Surg Endosc 1999;13(7):639-44.

[14] Karanjia ND, Corder AP, Bearn P, et al. Leakage from stapled low anastomosis after total mesorectal excision for carcinoma of the rectum. Br J Surg 1994;81(8):1224-6. 